\title{
ON CALCULATION METHODS AND RESULTS FOR STRAIGHT CYLINDRICAL ROLLER BEARING DEFLECTION, STIFFNESS, AND STRESS
}

\author{
Timothy L. Krantz \\ NASA \\ Cleveland, Ohio USA
}

\begin{abstract}
The purpose of this study was to assess some calculation methods for quantifying the relationships of bearing geometry, material properties, load, deflection, stiffness, and stress. The scope of the work was limited to two-dimensional modeling of straight cylindrical roller bearings. Preparations for studies of dynamic response of bearings with damaged surfaces motivated this work. Studies were selected to exercise and build confidence in the numerical tools. Three calculation methods were used in this work. Two of the methods were numerical solutions of the Hertz contact approach. The third method used was a combined finite element surface integral method. Example calculations were done for a single roller loaded between an inner and outer raceway for code verification. Next, a bearing with 13 rollers and all-steel construction was used as an example to do additional code verification, including an assessment of the leading order of accuracy of the finite element and surface integral method. Results from that study show that the method is at least first-order accurate. Those results also show that the contact grid refinement has a more significant influence on precision as compared to the finite element grid refinement. To explore the influence of material properties, the 13-roller bearing was modeled as made from Nitinol 60, a material with very different properties from steel and showing some potential for bearing applications. The codes were exercised to compare contact areas and stress levels for steel and Nitinol 60 bearings operating at equivalent power density. As a step toward modeling the dynamic response of bearings having surface damage, static analyses were completed to simulate a bearing with a spall or similar damage.
\end{abstract}

\section{INTRODUCTION}

The motivation for this work was to prepare for studies of the dynamic response of bearings with damaged surfaces. The purpose of this study was to assess some calculation methods for quantifying the relationships of bearing geometry, material properties, load, deflection, stiffness, and stress. One of the calculation methods studied herein was an approach that makes use of a combined finite element and surface integral method for contacting surfaces [1-3]. The method has proven very powerful for studying a variety of gearing and bearing problems. This approach can offer valuable insights for situations when elastic deformations, rigid body movements, and/or wear and damage have significant effects on the shapes and orientations of contacting surfaces [4-8]. Computing speed and memory of personal computers are now of sufficient performance to consider using simulations to study forced vibration response of bearings and gears having pitted surfaces [9]. To prepare for such studies, bearing and gear computing tools including pre- and post- processors for the combined finite element and surface integral method have been developed. Studies were selected to exercise and build confidence in the numerical tools.

The scope of this work was to analyze two-dimensional models of straight cylindrical roller bearings. Guo and Parker [10] have conducted a study of bearing contact problems using both two-dimensional and three-dimensional models. Guo and Parker were particularly interested in calculating bearing stiffness properties. They noted for certain cases significant differences between the three-dimensional and twodimensional approaches when calculating stiffness properties. Herein, the scope was limited to the two-dimensional approach consistent with the motivations for this study. While Guo and Parker modeled bearings with no damage, bearings with damaged surfaces were considered herein. One must keep in mind the limitations of the two-dimensional approximation when studying the literature and when selecting an approach for a particular study, analysis, or design situation. Even given the limitations, the two-dimensional model can provide useful insights. 


\section{ANALYSIS METHODS}

For many engineering situations, the contact deflection and state of stress in a bearing can be effectively studied using the approach of Hertz published in 1896 [11]. The classical approach to solution of the Hertz equations requires calculation of complete elliptic integrals of the first and second kind. Jones [12] published a calculation method for the application of Hertz theory to bearings. This approach made use of charts to reduce the calculation burden in the era when electronic aids for calculations were not widely available. Harris [13] describes methods for bearing analyses including an iterative numerical technique to obtain rolling element loads. Hamrock [14] provides another approach to the numerical solutions for contacting bodies for both elliptical and line contact situations. Hamrock's approach for line contact problems made use of equations published by Engineering Sciences Design Unit [15]. The Engineering Sciences Design Unit later published an update to this publication [16]. Although the Hertz approach was published more than 100 years ago, development of fast and increasingly accurate approximate solutions for the Hertz equations continues. For example, in 2006 Antoine, et al. [17] published a set of algebraic equations for approximate, precise solutions of the Hertz equations for elliptical contacts.

Some researchers have especially focused on methods for calculating bearing stiffness. Jones provided an early and comprehensive treatment of elastically constrained bearings [18]. His publication provided 224 equations used to study and solve various aspects of shaft and bearing systems which were modeled using statically-indeterminate, nonlinear elastic equations. Singh and Lim [19-21] studied the limitations of bearing analysis models and methods used to determine bearing stiffness properties. They provided a new formulation to estimate bearing stiffness properties and applied the method to study vibration transmitted by the bearings. Guo and Parker [10] have made use of a combined finite element and surface integral method to study bearing stiffness. They provide an overview of the literature for computing bearing stiffness, and they compare and contrast the solutions obtained by various methods.

In the present work, straight cylindrical bearings were modeled using three computing tools. The first computing tool selected for the present work is a modified version of the Engineering Science Design Unit approach [16]. For the inner raceway and the rolling elements, the equations were used directly. However, the published ESDU equations for the elastic approach apply only for two cylinders in contact, and so these were not used for the elastic approach of the outer raceway member. The following modified method was used for the outer raceway. First the width of the contact was determined using the ESDU equations. Next the movement of the outer diameter of the outer raceway relative to the rolling element center was approximated as that of a rectangular block of finite thickness interacting with the same roller and matching the contact width of the roller and inner raceway. The thickness of the block matched the thickness of the outer raceway. The movement of the block was calculated via an approximate elasticity solution described by Johnson [22]. This method will be referred to as the "modified ESDU" method in the remainder of this document.

The second computing tool selected for the present work was one based on the method of Lim and Singh [19-21]. Calculations for this method were done using executable code "REBM" provided to the author by Lim [23] and the method will be referred to as "REBM".

The third tool used for the present work was a combined finite element and surface integral method [24]. Analyses were done to exercise the computing tool and the associated preprocessor and post-processor tools for bearing modeling [9]. This method will be referred to as the "FE-SI" (finite element surface integral) method.

The remainder of this manuscript is organized as a set of case studies. Each case study includes a description of geometry and material properties, loads, and results. Following is a listing of the case studies included:

Case Study A. The contact condition for a single rolling element was studied. An idealized steel bearing having only one rolling element was defined and used to study deflection, stresses and stiffness. The roller size was varied while maintaining the bearing pitch diameter. Case A also includes a study of the influence of the numerical grid sizes used for the FE-SI method.

Case Study B. The load distribution of a statically loaded bearing with multiple rollers was studied. An example steel roller bearing with zero clearance was selected to study loads, deflection, and stiffness. This bearing example has also been studied by Guo and Parker (Ref. 10).

Case Study C. The influence of material properties on bearing response was examined. The geometry of the bearing for this case matched that of Case B but the material was modeled as Nitinol 60 rather than steel. Calculations were done to compare stresses of a steel versus a Nitinol 60 bearing for equivalent load density.

Case Study D. The influence of a pitted bearing surface was studied. The geometry and materials property matched that of Case B, but damage (missing material) was modeled on the outer raceway at the location in contact with roller \#1. Only the FE-SI method was used for this case study. The change in the bearing deflection because of surface damage was studied.

\section{CASE STUDY A - SINGLE ROLLING ELEMENT}

This case study was done to compare and assess various aspects of the calculation methods. The selected geometry and loading condition was a single loaded straight roller between two raceways. This sort of idealized bearing was selected to provide a simple example for studying and comparing the numerical methods. The bearings for Case Study A are defined in Table 1 and depicted in Figure 1. The roller was assumed as positioned on the positive-x axis. The bearings of course do not represent practical applications. However, this arrangement provides for all the force to be carried by a single roller, providing ease of calculation and interpretation of results. 


\section{Case Study A - Modeling Details}

To begin the assessment of the numerical methods, the deflection and contact pressures were calculated for the bearings of Table 1 for an assumed radial displacement of the outer raceway outer diameter toward the bearing center. The displacement magnitude was $0.0254 \mathrm{~mm}$ and was directed along the $\mathrm{x}$-axis. Details of implementation for the three numerical methods were as follows.

The modified ESDU method comprises a set of algebraic equations providing an approximate solution of the Hertz equations for line contact. This method requires load as an input and calculates deflections and contact details. To study the problem at hand, trial-and-error was used to determine the load (to the nearest $0.5 \mathrm{~N}$ ) causing $-0.0254 \mathrm{~mm}$ of displacement of the outer diameter relative to the center of the inner raceway.

The REBM code includes an option to solve using displacement as an input and so the problem was solved directly avoiding trail-and-error iterations. To use the REBM code, a contact stiffness parameter value can be input directly or, optionally, the parameter value can be calculated by the code using elastic constant for steel and the provided geometry. In this work the contact stiffness parameter was calculated by the REBM code.

To solve the problem using the FE-SI method, boundary conditions must be specified. For this problem, the outer circumference of the outer raceway was constrained to remain a pure circle of the specified dimension. The movement of this circle was defined as $-0.0254 \mathrm{~mm}$ along the $\mathrm{x}$-axis. The inner circumference of the inner raceway was constrained as a rigid circle with zero displacement. The rollers bodies' inner diameters are rigid circles. One should not be mislead by the graphic of Figure 1. The model did not simulate hollow rollers. The roller bodies are free to move in the radial direction but cannot roll or move in the circumferential direction at any particular solution step. The rollers are positioned circumferentially according to the bearing kinematics for those studies requiring multiple time steps. In this work a convention was adopted to locate a roller on the positive $\mathrm{X}$-axis. The reaction forces on the raceways were calculated as part of the solution.

For the FE-SI method, one must select parameters to define the number of finite elements in each body and to define the size of contact cells used for the contact algorithm. In this work these parameters were systematically varied over a range of values to study the influence of these parameters and to study the leading order of accuracy.

A finite element mesh was defined to have elements of similar size in all bodies, reasonable aspect ratios, and element numbers to be able to refine the mesh in 50 percent increments successively twice. That is, to create refined meshes, a refinement factor $\mathrm{R}$ was used. Herein, $\mathrm{R}=1.5$ was used where $\mathrm{R}=$ ratio of length of element in mesh " $\mathrm{A}$ " to length of the same element in mesh "B". Figure 2(a-c) depicts meshes "A", "B", and " $C$ " using roller $A 2$. The elements have nodes at each of the displayed corners. Each cubic-order element has additional nodes not shown in the figure. Using this scheme, the number of elements in each body increases by a factor of 2.25 for each refinement. The number of finite elements total in the outer race, inner race, and a single roller for each of the three meshes used was: mesh "A", 4800 elements; mesh "B", 10800 elements; mesh "C", 24300 elements.

The FE-SI approach to contact problems requires selection for the size of the numerical contact grid or "cells". For each cell the contact pressure is a constant. One should expect that the solution will depend on both the size (i.e. density) of the finite elements and the size of the contact cells. The modified ESDU solution to this problem includes a calculation of the contact width and thus provided guidance for selecting the size of the contact cells. The FE-SI code used in this study allowed for a maximum of 41 cells to be used at each roller-raceway interface. The cells were to be refined in steps of 50 percent $(R$ $=1.5$ ), matching the approach used to refine the sizes of the finite elements. Using this information, the cell sizes were selected as listed in Table 2. All combinations of finite element size and cell size were analyzed. Table 3 provides identifiers for the cases analyzed

Table. 1 - BEARING DESCRIPTION FOR CASE STUDY A - (BEARING WITH ONE STRAIGHT CYLINDRICAL ROLLER)

\begin{tabular}{|l|l|}
\hline pitch diameter & $57.4961 \mathrm{~mm}$ \\
\hline diametral clearance & $0.000 \mathrm{~mm}$ \\
\hline roller axial length & $21.988 \mathrm{~mm}$ \\
\hline inner raceway diameter & $46.486 \mathrm{~mm}$ \\
\hline roller diameter, case A1 & $5.46 \mathrm{~mm}$ \\
\hline roller diameter, case A2 & $11.00 \mathrm{~mm}$ \\
\hline roller diameter, case A3 & $22.00 \mathrm{~mm}$ \\
\hline outer diameter, case A1 & $104 \mathrm{~mm}$ \\
\hline outer diameter, case A2 & $104 \mathrm{~mm}$ \\
\hline outer diameter, case A3 & $127 \mathrm{~mm}$ \\
\hline Young's modulus & $206.8 \mathrm{GPa}$ \\
\hline Poisson's ratio & 0.30 \\
\hline
\end{tabular}

Note: width of outer and inner raceways match the axial length of the roller 
Table 2 - CONTACT CELL SIZES

\begin{tabular}{|c|c|}
\hline cell size choice & width of one cell $(\mathrm{mm})$ \\
\hline 1 & .02286 \\
\hline 2 & .01543 \\
\hline 3 & .01016 \\
\hline
\end{tabular}

Table 3 - CELL AND MESH SIZES BY ANALYSIS CASE

\begin{tabular}{|c|c|c|c|}
\cline { 2 - 4 } \multicolumn{1}{c|}{} & \multicolumn{3}{|c|}{ mesh choice (see Fig. 2 } \\
\hline $\begin{array}{c}\text { cell size choice } \\
\text { (see Table 2) }\end{array}$ & A & B & C \\
\hline 1 & case 1 & case 4 & case 7 \\
\hline 2 & case 2 & case 5 & case 8 \\
\hline 3 & case 3 & case 6 & case 9 \\
\hline
\end{tabular}
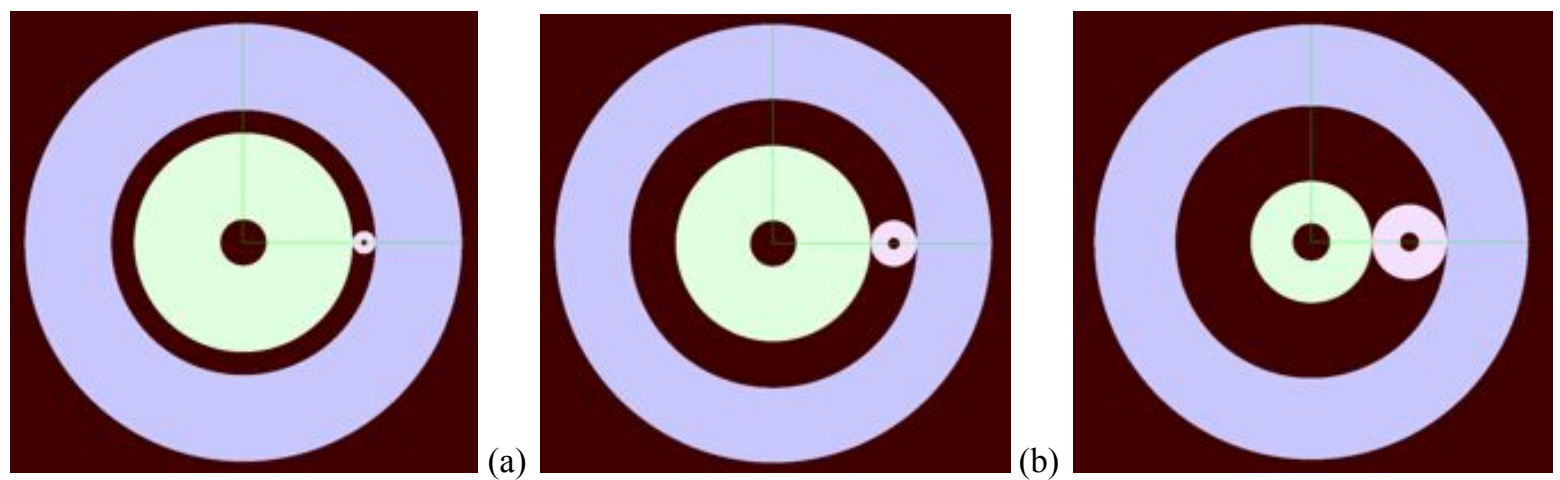

(c)

Figure 1. IDEALIZED BEARINGS USED TO STUDY NUMERICAL METHODS OF ANALYSIS. (A) ROLLER SIZE A1, (B) ROLLER SIZE A2, (C) ROLLER SIZE A3.
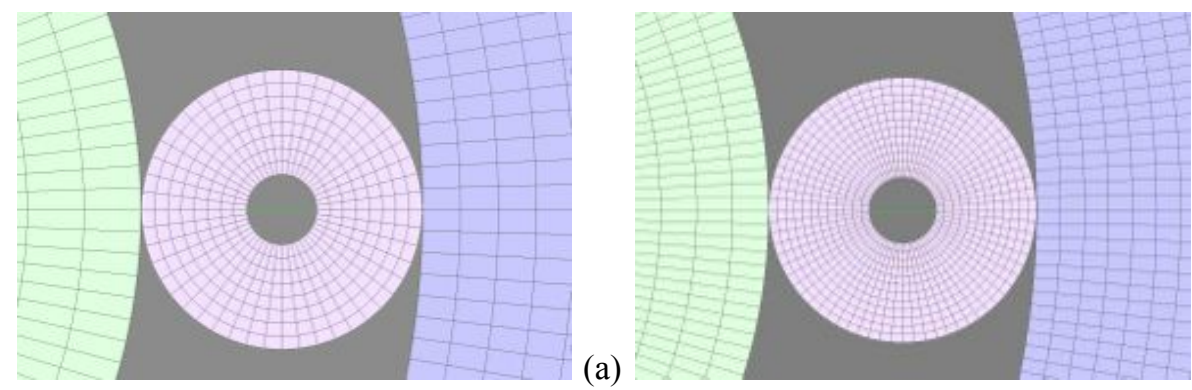

(b)

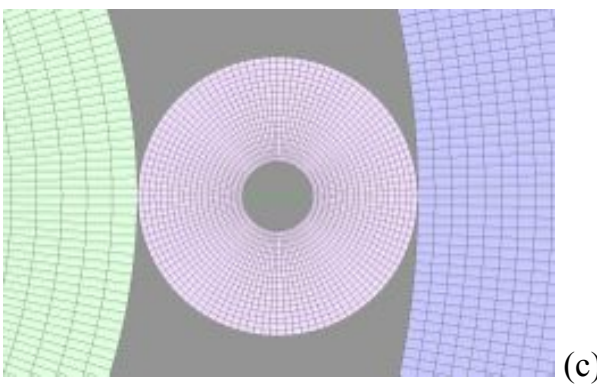

Figure 2. FINITE ELEMENTS OF INCREASING MESH DENSITY USING REFINEMENT FACTOR OF R=1.5.

\section{Case Study A - Results for Deflection and Contact Pressures}

First the results for elastic deformation are presented. The movement of the center of the inner raceway relative to the outer diameter of the outer raceway was calculated for a range of loads. For this example, the FE-SI method was executed using the parameters for mesh size and contact cell size per "case 5 " of Table 3 . The calculations were done for the three rollers sizes depicted in Fig. 1. Results of the calculations are plotted in Fig. 3. Note that the REBM code predicts the stiffest response (largest load supported for a given displacement), followed by the FE-SI method and then the modified ESDU method. The significantly stiffer response predicted by the REBM code is a result of using the code option to calculate the contact stiffness parameter rather than input a value directly. When a user calculates the parameter using the REBM code rather than input a numeric value, then the following equation is used to calculate the stiffness parameter using units of Newton for force and $\mathrm{mm}$ for length.

$$
K_{l}=7.86 \times 10^{4} l\left(\frac{8}{9}\right) \text { where } l \text { is length of roller }
$$

Equation (1) can be found in Harris [13] with no qualifiers or discussion about the precision of the relation. While this equation may provide adequate solutions for some engineering uses, a study of the elasticity equations, literature, and the results of this study suggest that user's of the REBM code 
should carefully consider the limited precision of this relation. Optionally, user's of the REBM code can estimate the contact stiffness by another method, and then can provide a more precise numerical value for the contact stiffness parameter via the input file.

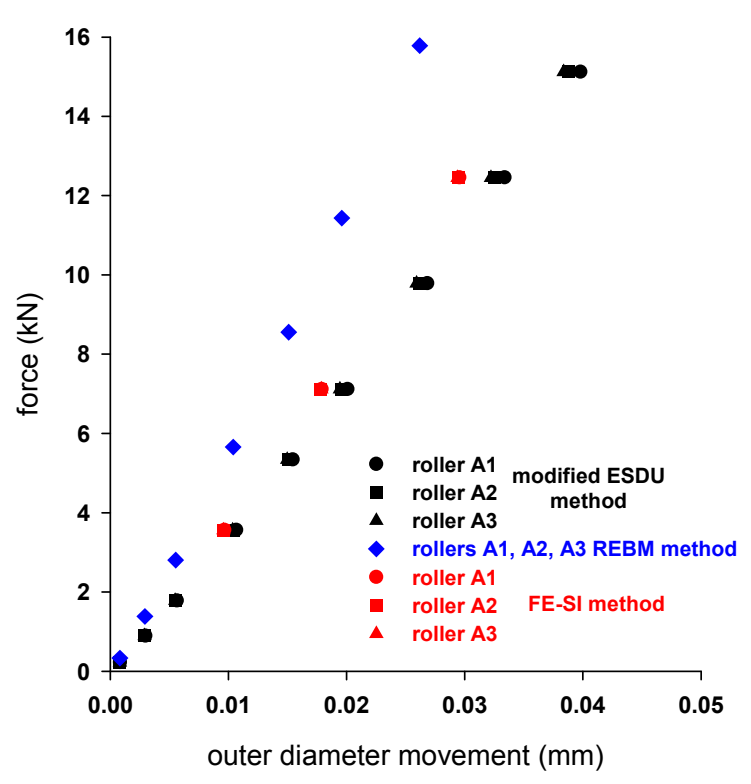

Figure 3. CALCULATED REACTION FORCES FOR A RANGE OF RADIAL DISPLACEMENTS FOR THE EXAMPLE BEARING OF FIGURE 2(B).

The results of Figure 3 include results for three different roller sizes while maintaining a constant value for the pitch diameter. The force and deflection results are essentially insensitive to the roller size, although the modified ESDU method does predict slight differing response for the three roller sizes. The REBM method does not use the roller size directly, and so only one result is provided. The force-deflection trend has a slight deviation from a linear relationship, a result consistent with the literature.

Both the modified ESDU and FE-SI methods make use of the outer raceway outer diameter for calculation of elastic approach. To assess the influence, the elastic approach was calculated for a radial load of $12.4 \mathrm{kN}$ and a range of values for the outer diameter. To complete this calculation using the FE-SI method, the finite element mesh and contact cell size used were those for case 5 of Table 3. Results of the calculations are provided in Figure 4. Note that the elastic approach increases as the outer diameter increases. Both methods provided similar trends. The elastic approach changes about $10 \%$ for the given range of values of the outer diameter. This example illustrates that for precise modeling of bearing deflection, the mounting conditions should be modeled carefully. In these examples, the innermost and outermost diameters were modeled as rigid circles. This modeling approach may or may not be suitable depending on the application and precision of results required for analysis or design.

Further insight about bearing stress distributions and deformation can be obtained by viewing results using graphical post-processing tools. Graphical displays of results for roller size A2 of Table 2 are provided in Figures 5-8. The maximum principle stress plots of Figures 5 and 6 closely resemble images in the literature of photoelastic studies of roller bearing stresses [for example, Ref. 13]. The pressure distribution plot of Fig. 7 illustrates that the predicted contact pressure is a close match to the parabolic distribution that was assumed by Hertz. Figure 8 shows the maximum principle stresses displayed on a deformed roller with deformations exaggerated by a factor of 200. Although difficult to discern solely from the graphic, the roller diameter expands slightly along the axis orthogonal to the contact load. The modified ESDU method and the REBM method do not include this subtle effect in the calculation procedures. The graphical tools illustrated herein proved to be useful for gaining insight and for making certain that the modeling inputs were mistake free.

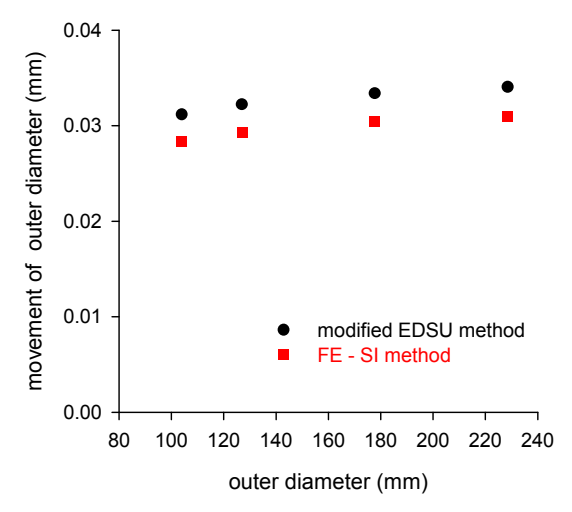

Figure 4. PREDICTED ELASTIC APPROACH OF OUTER RACEWAY TOWARD THE BEARING CENTER FOR CASE OF 12.4 KN RADIAL LOAD AS A FUNCTION OF SIZE OF OUTER DIAMETER.

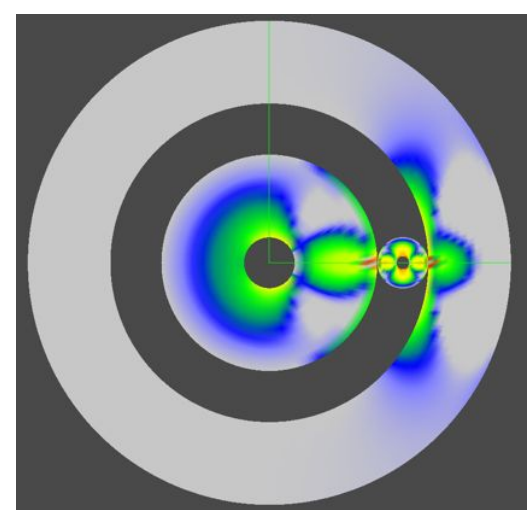

Figure 5. MAXIMUM PRINCIPLE STRESS PLOT FOR CASE 5 OF TABLE 2. 


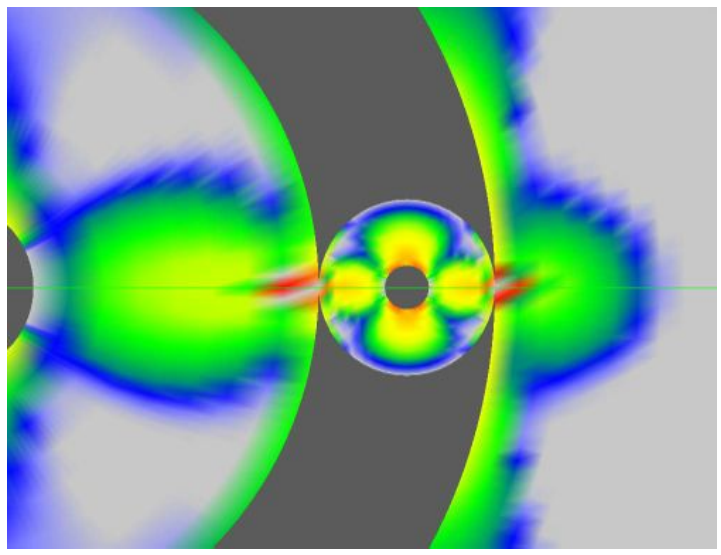

Figure 6. CLOSEUP VIEW OF FIG. 4, MAXIMUM PRINCIPLE STRESS PLOT FOR CASE 5 OF TABLE 2.

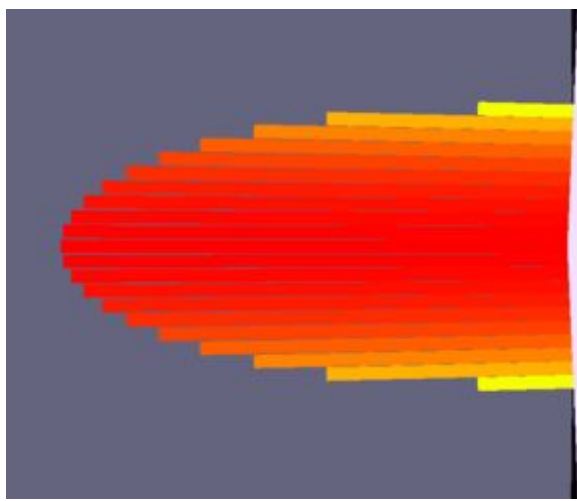

Figure 7. CONTACT PRESSURE DISTRIBUTION ON THE INNER RACEWAY FOR CASE 5 OF TABLE 2.

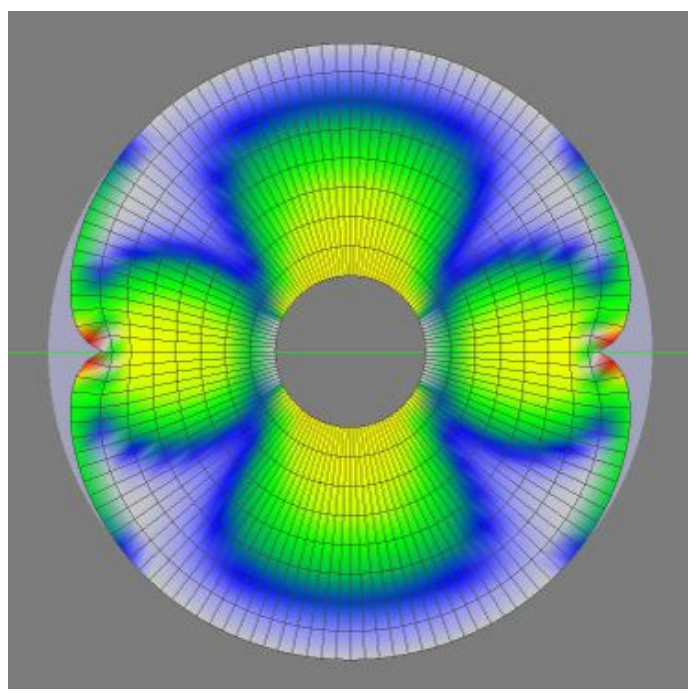

Figure 8. MINIMUM PRINCIPLE STRESS FOR THE ROLLER DEPICTED ON DEFORMED GEOMETRY, DEFORMATIONS EXAGGERATED BY A FACTOR OF 200.

To explore the influence of the selection of finite element mesh size and contact cell size on the predicted loads and contact pressures when using the FE-SI method, results were calculated for a range of modeling parameters per Table 3. For these examples a radial displacement of the outer diameter of $0.0254 \mathrm{~mm}$ was imposed. Results of those calculations are provided in Table 4 . The maximum and minimum values for the load and contact pressures are highlighted in Table 4. For a wide range of modeling parameters, the predicted reaction load varied by about $10 \%$ and the predicted maximum contact pressures varied by about $5 \%$. These results of Table 4 were also used to study the leading order of accuracy, the next topic for discussion.

Table 4 - ANALYSIS RESULTS USING FE-SI METHOD FOR ALL NINE CASES DEFINED IN TABLE 3.

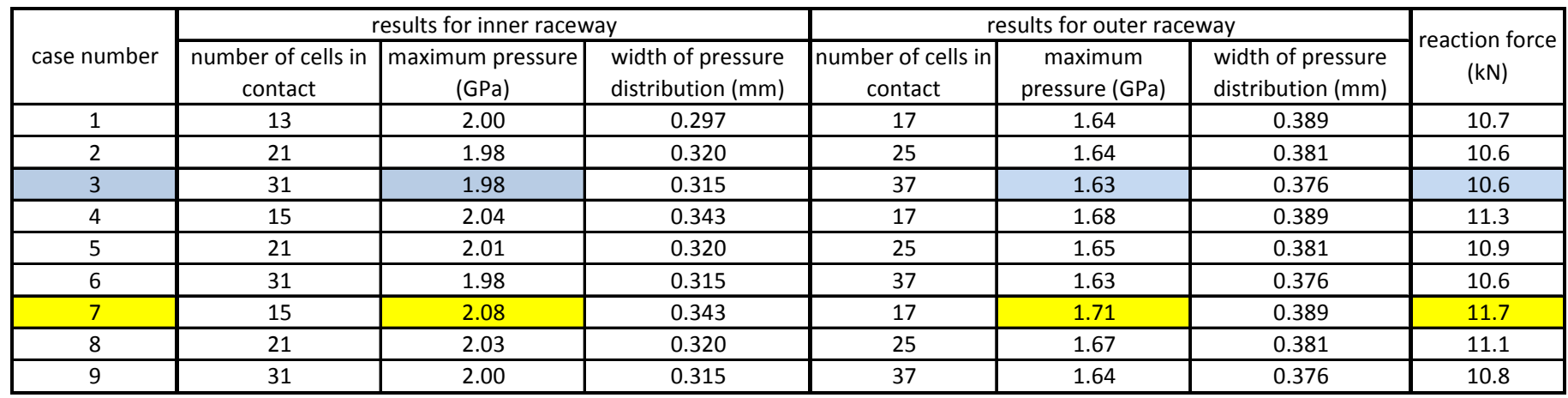




\section{Leading Order of Accuracy}

While the results provided in Table 4 provides some information about the selection of contact cell and finite element grid sizes as relates to the precision of results, the leading accuracy of computational mechanics codes can be studied in a more formal manner. The ASME Performance Test Code Committee 60 was formed in recognition of the need for guidelines for the verification and validation of computational mechanics codes. The leading orders of accuracy calculations were done in the spirit of the ASME guide for verification and validation of computational solid mechanics codes [25].

Guo and Parker [10] used the FE-SI method in threedimensional mode to study some bearing contact problems. They quantified the order accuracy effect of the finite element mesh density. A similar study was done herein using the FE-SI method in two-dimensional mode. While Guo and Parker reported results for finite element mesh size, herein both finite element and contact cell size was studied. Guo and Parker [10] proposed using the following equation to assess the relationship of the finite element grid size used for the FE-SI method to the leading order of accuracy.

$$
p_{1}=\frac{\log \left(\frac{V_{h 3}-V_{h 1}}{V_{h 3}-V_{h 2}}\right)}{\log (\mathrm{r})}
$$

Here, $\mathrm{V}$ is the solution, $\mathrm{h}$ denotes the element size, and $\mathrm{h} 1$ $>\mathrm{h} 2>\mathrm{h} 3, \mathrm{r}=\mathrm{h} 2 / \mathrm{h} 1=\mathrm{h} 3 / \mathrm{h} 2$, and $\mathrm{p} 1$ is an approximate solution of the leading order of accuracy. Additional background about this approach for leading order of accuracy is provided by Roache (Ref. 26). Herein, it is proposed that the equation can be applied to refinement of the finite element grid and also, separately, to refinement of the contact cell size.

The reaction force was considered as the solution variable of interest. Results for contact reaction forces as the contact cell size and finite element grid size were varied systematically are organized and presented in a matrix format in table 5. In this table, the contact cell size is a constant on any row, and contact cell size decreases from the top toward the bottom row. The finite element size is a constant value for any column, and the finite element length decreases from the left toward the right. Note that the reaction force tends to increase as the element size decrease. However, for the contact cell size the reaction force tends to decrease at the contact cell size decreases. One can apply equation 2 to calculate a value for $\mathrm{p} 1$ for each row or column of Table 5. Results of such calculations are provided in Table 6 . The values for the leading order of accuracy, shown in Table 6 , for the finite element size influence (rows) are similar to those determined by Guo and Parker (Ref. 10) for a similar three-dimensional approach to bearing contact problems. As a reminder, the contact cell size is a constant for any row while the finite element mesh size is a constant for any column. The leading orders of accuracy estimates, $\mathrm{p}_{1}$, are greater than 1.0 for all of the nine tested cases. Also note that the orders of accuracy values are generally smaller for the columns as compared to the rows. This implies that numeric truncation error tends to be controlled more by the contact cell size compared to the finite element grid size. When using the FE-SI method the contact cell size needs to be selected carefully as it has the biggest influence on numerical truncation error and also has a significant influence on the solution times.

Table 5. REACTION FORCES FOR ALL FE-SI ANALYSES OF CASE STUDY A.

\begin{tabular}{|c|c|c|c|}
\cline { 2 - 4 } \multicolumn{1}{c|}{} & \multicolumn{3}{c|}{ finite element mesh choice } \\
\hline contact cell size choice & $\mathrm{A}$ & $\mathrm{B}$ & $\mathrm{C}$ \\
\hline 1 & $10.7 \mathrm{kN}$ & $11.3 \mathrm{kN}$ & $11.7 \mathrm{kN}$ \\
\hline 2 & $10.6 \mathrm{kN}$ & $10.9 \mathrm{kN}$ & $11.1 \mathrm{kN}$ \\
\hline 3 & $10.6 \mathrm{kN}$ & $10.6 \mathrm{kN}$ & $10.8 \mathrm{kN}$ \\
\hline
\end{tabular}

\section{Table 6. RESULTS OF LEADING ORDER OF ACCURACY CALCULATIONS.}

\begin{tabular}{|c|c|}
\hline Ref. Table 5 & value of $\mathrm{p} 1$ \\
\hline row 1 & 1.45 \\
\hline row 2 & 1.78 \\
\hline row 3 & 2.66 \\
\hline column 1 & 1.49 \\
\hline column 2 & 1.24 \\
\hline column 3 & 1.28 \\
\hline
\end{tabular}

\section{CASE STUDY B - BEARING WITH A FULL SET OF ROLLERS}

To further study the numerical methods for bearing contact problems, an example bearing geometry that has been studied by Guo and Parker (Ref. 10) was selected for study and exercise of the numeric codes. The geometry of the bearing is provided in Table 7. This example bearing has zero internal clearance. The outer diameter was assumed to be displaced by $0.010 \mathrm{~mm}$. It was desired to determine the reaction force, maximum pressures, and bearing stiffness using each of the three numerical methods. The bearing geometry is depicted in Fig. 9. The finite element mesh selected for this case study is depicted in Fig.10. In such a bearing, the load is shared among several rolling elements. To solve the problem by the modified ESDU method, the elastic approach for each rolling element was calculated from the bearing geometry. The radial load at each rolling element was determined via trail-error iterations, and the total reaction load was found by summing the $\mathrm{x}$ components of the radial forces. The bearing was also studied using the REBM code using the code's internal estimate of the contact stiffness parameter. Finally, the bearing was studied using the FE-SI method by imposing the displacement of the outer raceway body. 
Table 7. GEOMETRY AND MATERIAL PROPERTIES OF BEARING FOR CASE STUDIES B, C, AND D.

\begin{tabular}{|l|l|}
\hline \multicolumn{2}{|c|}{ geometry } \\
\hline roller type & straight cylinder \\
\hline number rollers & 13 \\
\hline roller diameter & $7.500 \mathrm{~mm}$ \\
\hline roller length & $8.600 \mathrm{~mm}$ \\
\hline pitch diameter & $39.00 \mathrm{~mm}$ \\
\hline outer diameter & $71.12 \mathrm{~mm}$ \\
\hline clearance & $0.000 \mathrm{~mm}$ \\
\hline \multicolumn{2}{|c|}{ material properties } \\
\hline \multicolumn{2}{|c|}{ example BRG-S and BRG-S-2 } \\
\hline \multicolumn{2}{|c|}{ example BRG-N } \\
\hline Young's modulus & $207 \mathrm{GPa}$ \\
\hline Poisson's ratio & 0.3 \\
\hline \multicolumn{2}{|c|}{$114 \mathrm{GPa}$} \\
\hline Young's modulus & 0.3 \\
\hline Poisson's ratio
\end{tabular}

For this case study it was desired to calculate bearing stiffness properties. Guo and Parker [10] have proposed use of a 2nd order central difference approach to determine bearing stiffness using the FE-SI method. The suggestion for a 2nd order approach was based on the study of the leading order of accuracy of FE-SI example calculations. The central difference equation as was used by Guo and Parker and also used herein follows.

$$
k\left(q_{0}\right)=\frac{F\left(q_{0}+\delta q\right)-F\left(q_{0}-\delta q\right)}{2 \delta q}
$$

In this equation, $\mathrm{F}$ represents the reaction force and q represents the deflection. To use the formula one must select a "step size" for the deformation represented as $\delta \mathrm{q}$. Guo and Parker studied the optimal step size based on example calculations and also based on computing machine precision. Using their results for guidance, a step size of 5E-6 times the nominal deflection was selected for the study herein. Since the nominal imposed deflection used herein was $0.010 \mathrm{~mm}$, a $\delta q$ equal to $5 \mathrm{E}-8 \mathrm{~mm}$ was selected. The same step sizes were used (in separate calculations) for both the $\mathrm{X}$ - and the $\mathrm{Y}$ - directions to calculate stiffness terms Kxx, Kyy,and Kxy using the FE-SI method. The same approach (including same step size) was used herein to estimate Kxx using the modified ESDU method. This required determining the radial loads on each rolling element via trailerror iterations to nine significant figures. The REBM code approach makes use of derivatives of analytical expressions for stiffness terms (Ref. 19-21).

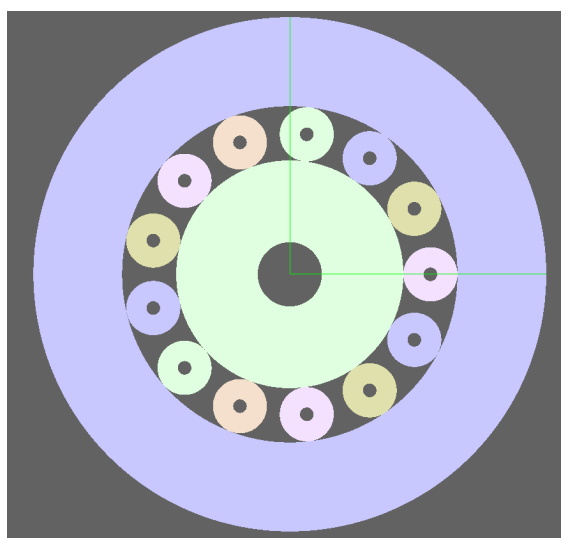

Figure 9. ILLUSTRATION OF BEARING USED FOR CASE STUDIES B, C, AND D.

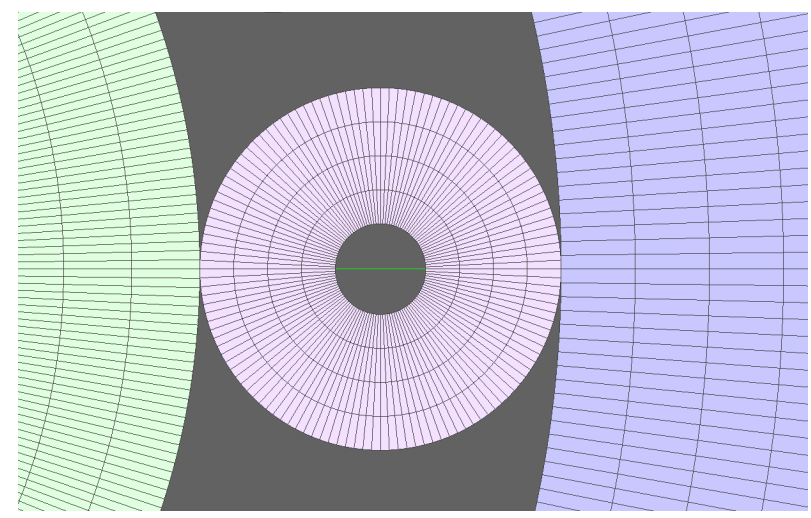

Figure 10. FINITE ELEMENT MESH USED FOR THE FE-SI METHOD AND CASE STUDY B, C, AND D.

A graphical display of results using the FE-SI method is provided in Figure 11. Because of zero internal clearance, all rollers to the right of the bearing center carry some radial load. Of course, the roller located on the $\mathrm{x}$-axis is the most heavily loaded roller. A summary of the results for all calculation methods is provided in Table 8. The reaction load ranged from the lowest value of $4.5 \mathrm{kN}$ using the modified ESDU method to the largest value of $10.6 \mathrm{kN}$ using the REBM method. The reaction load using the FE-SI method was $5.0 \mathrm{kN}$, a value inbetween those of the other two methods but closer in agreement to the modified ESDU value. It must be noted that the REBM code includes an option to input a value for the contact stiffness, but such option was not exercised in this study. The estimates of the stiffness Kxx ranged from 470 to $1133 \mathrm{kN} / \mathrm{mm}$. Guo and Parker [10] also estimated the Kxx term for this bearing using the FE-SI method in three-dimensional mode. For the bearing operating with $5.0 \mathrm{kN}$ load, Guo and Parker calculated a value for $\mathrm{Kxx}=400 \mathrm{kN} / \mathrm{mm}$ using FE-SI method in three dimensions while herein $\mathrm{Kxx}=540 \mathrm{kN} / \mathrm{mm}$ using FESI method in two-dimensional mode. The stiffness terms Kyy and Kyx were also determined using the FE-Si and REBM method. From both methods it was found that the Kyy stiffness 
term is approximately equal to the Kxx stiffness term while the cross-coupling Kyx stiffness term is at least 3 orders of magnitude smaller than the diagonal terms. These calculations and results provide some confidence and verification of the FESI code. The studies also highlight some limitations of modeling straight cylindrical bearings using the idealized linecontact two-dimensional approach. Further confidence could be gained through validation studies comparing to experimental data, but especially for bearing stiffness properties the data in the open literature is very sparse. Results from clever and careful experiments to measure bearing stiffness properties would be a welcome addition to the literature.

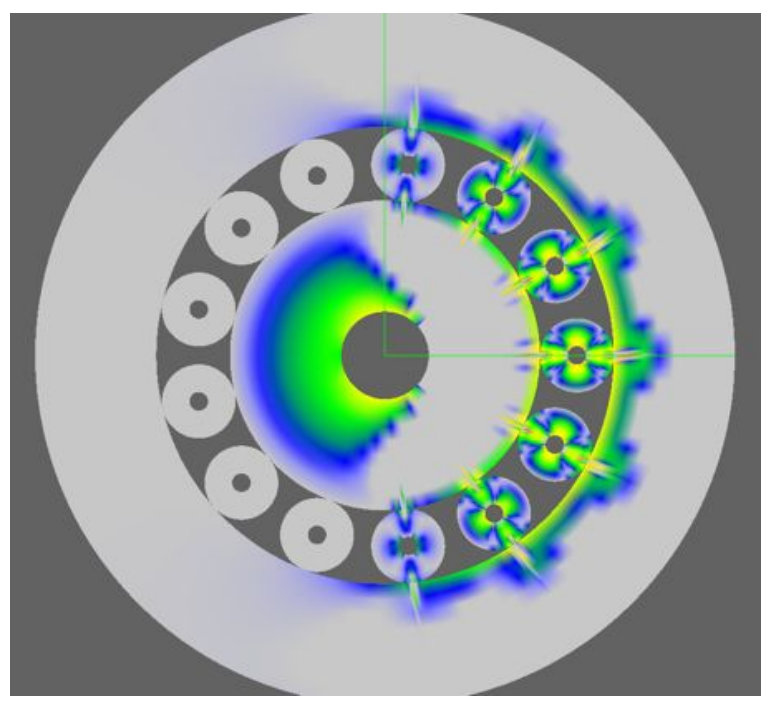

Figure 11. MAXIMUM PRINCIPLE STRESS RESULT FOR CASE STUDY B.

Table 8. CALCULATED RESULTS FOR EXAMPLE BEARING BRG-S [TABLE 7] FOR IMPOSED MOVEMENT OF OUTER RACEWAY OF -0.010 MM IN THE X-DIRECTION.

\begin{tabular}{|r|c|c|c|}
\cline { 2 - 4 } \multicolumn{1}{c|}{} & \multicolumn{3}{c|}{ Analysis Method } \\
\hline calculated result & Modified EDSU & REBM & FE-SI \\
\hline reaction force $(\mathrm{kN})$ & 4.5 & 10.6 & 5.0 \\
\hline max. pressure, inner raceway $(\mathrm{GPa})$ & 1.4 & N/A & 1.5 \\
\hline max. pressure, outer raceway $(\mathrm{GPa})$ & 1.1 & N/A & 1.2 \\
\hline contact width, inner raceway $(\mathrm{mm})$ & 0.15 & N/A & 0.16 \\
\hline contact width, outer raceway $(\mathrm{mm})$ & 0.18 & N/A & 0.20 \\
\hline stiffness, Kxx, $(\mathrm{kN} / \mathrm{mm})$ & 470 & 1133 & 540 \\
\hline stiffness, Kyy, $(\mathrm{kN} / \mathrm{mm})$ & N/A & 1024 & 540 \\
\hline stiffness, Kyx, $(\mathrm{kN} / \mathrm{mm})$ & N/A & 0.02 & 0.00 \\
\hline
\end{tabular}

\section{CASE STUDY C - BEARING WITH MATERIAL PROPERTIES OF NITINOL 60}

Studies have been done to assess the potential for Nitinol 60 as a bearing material [27, 28]. For aerospace applications of mechanical components, the load-carrying density is one important figure of merit. For example, the load-carrying density of a gearbox is often stated as output power per unit mass of the gearbox [29]. For this study, the load-carrying density was defined as force per unit mass, and calculations were done to compare the state of stress of a steel bearing to a Nitinol 60 bearing operating at equal load-carrying density. The ratio of the density of Nitinol 60 relative to steel is about 0.85 . The ratio of the elastic modulus of Nitinol 60 relative to steel is about 0.55 The FE-SI computing tool was used to assess the stress conditions of a steel bearing (example BRG-S) and a Nitinol 60 bearing (example BRG-N) operating at equivalent load-carrying density. The geometry and material properties used were per Table 7. An intermediate example was also calculated, example BRG-S-2, the bearing having material properties of steel but operating at the load of the BRG-N, Nitinol 60 bearing. This was done to illustrate the separate effects of reduced load intensity and reduced stiffness on the state of stress. Results of the calculations are shown in Table 9. The relatively low elastic modulus of the Nitinol material has a significant effect on the contact stresses. For equivalent loadcarrying density, the ratio of maximum contact pressures for the Nitinol 60 bearing relative to the steel bearing is about 0.68 . The relative movement of the outer ring toward the inner ring is of course greater for the Nitinol 60 bearing compared to the steel bearing. Comparing the results for Nitinol bearing BRG-N and BRG-S-2 having the elastic properties of steel but operating at the reduced load of the Nitinol 60 , one notes the reduced stress in the Nitinol 60 bearing at equivalent load- 
carrying density is largely an elastic effect. This effect should be kept in mind as research is carried out to explore the capabilities of Nitinol 60 as a bearing material.

\section{CASE STUDY D - BEARING WITH PITTED SURFACE}

The primary motivation of this work was preparation for studies of dynamic response of bearings with damaged surfaces. As a first step the FE-SI numerical tool was exercised using static solution mode. An example problem was prepared to have a surface pit located on the outer raceway member located at the x-axis. The bearing geometry for this example matched that of case study B. The load imposed on the bearing was a $4.8 \mathrm{kN}$ force directed along the $\mathrm{x}$-axis. To create an example pit, the sector of an ellipse was defined. The pit geometry defines the deviation from perfect form. The pit width used was approximately the size of the contact pressure width when the surface is undamaged. The different pit depths were defined where the pit depth equals that of the nominal pit times a depth factor. The nominal pit depth was selected as 0.0088 $\mathrm{mm}$ which is approximately the depth locating the maximum shears stress for the undamaged bearing. The three multiplicative pit depth factors used equaled 0.5, 1.0, and 2.0. The pit profile of the deepest pit (depth factor $=2.0$ ) was as illustrated in Fig. 12. The example problems were solved to determine the movement of the outer race member toward the bearing center from elastic deformations. Several solutions were obtained while positioning roller \#1 near and over the location of the pit.

The movement of the outer raceway as a function of the roller position and pit depth is plotted in Fig. 13. As the deepest pit is engaged, the outer ring movement increases from a value of about $0.010 \mathrm{~mm}$ when the roller is located fully on the undamaged surface to a value of about $0.0145 \mathrm{~mm}$ when the roller is located fully over the pit location. The patterns of maximum principle stress for the conditions of undamaged and damaged outer raceways for roller position directly on the $\mathrm{x}$ axis are provided in Fig. 14. For the deepest pit and static solution (slow speeds), the roller will become fully unloaded when the roller is over the pit location. For the most shallow pit studied, the roller becomes only partially unloaded when the roller is directly over the pit location. This example calculation demonstrated the FE-SI method for bearing surfaces with damage. It is anticipated that using such a computing tool in dynamic solution mode will provide insights for relating bearing surface damage magnitude to the expected magnitude and spectral content of forced vibration response.

Table 9 - RESULTS FOR STEEL AND NITINOL 60 BEARINGS.

\begin{tabular}{|c|c|c|c|}
\hline example & BRG-S & BRG-S-2 & BRG-N \\
\hline reaction force $(\mathrm{kN})$ & 5.00 & 4.24 & 4.24 \\
\hline ring movement (mm) & .0104 & .0086 & 0.0155 \\
\hline max. pressure, inner raceway (GPa) & 1.48 & 1.36 & 1.01 \\
\hline max. pressure, outer raceway (GPA) & 1.21 & 1.12 & 0.83 \\
\hline contact width, inner raceway (mm) & 0.162 & 0.147 & 0.196 \\
\hline contact width, outer raceway (mm) & 0.199 & 0.171 & 0.235 \\
\hline
\end{tabular}

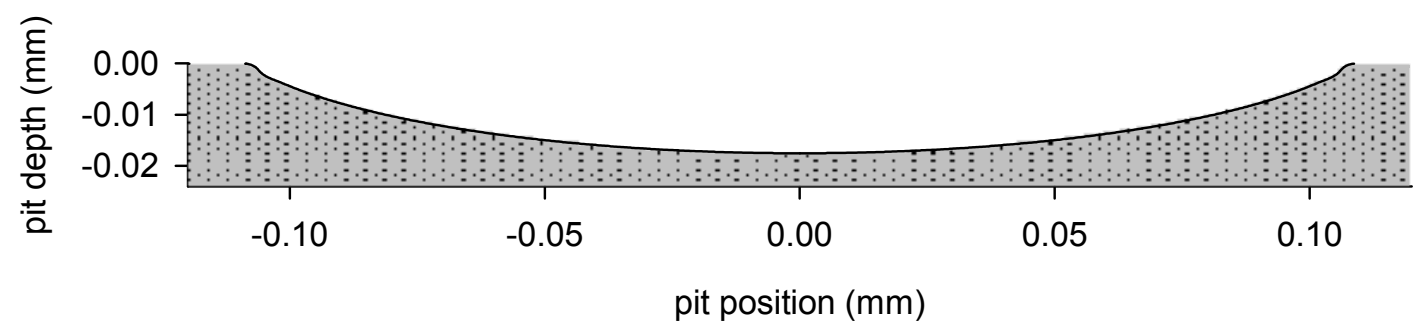

Figure 12. EXAMPLE PIT PROFILE (DEVIATION FROM PERFECT FORM) THAT WAS INTRODUCED ON THE OUTER RACEWAY. 


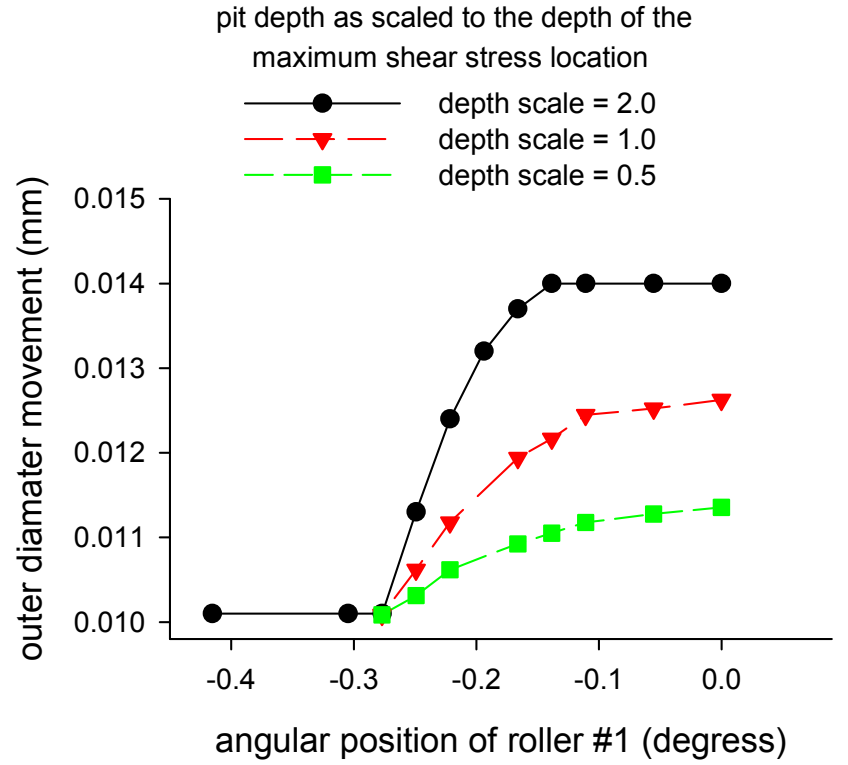

Figure 13 - MOVEMENT OF OUTER RACEWAY TOWARD BEARING CENTER AS FUNCTION OF THE POSITION OF ROLLER NUMBER ONE ASSUMING STATIC LOADS. SOLUTION WAS OBTAINED VIA FE-SI METHOD

\section{SUMMARY}

The purpose of this study was to assess some calculation methods for quantifying the relationships of bearing geometry, material properties, load, deflection, stiffness, and stress. Three numerical tools were used completing four case studies, and results were gathered and compared. The case studies were selected to verify and build confidence in the particular implementations of the numerical tools and also to examine some emerging technology trends. The following specific results and observations were obtained.
1. The elastic movement of the outer raceway toward the bearing center is a function of the outer raceway diameter. Some of the classical methods used to estimate contact stiffness of line contacts cannot capture this, and other, subtle effects.

2. The particular implementation of the combined finite element - surface integral (FE-SI) method was shown to have a leading order of accuracy greater than 1.0 over a wide range of finite element size and contact cell size selections. The contact cell size influences the order accuracy more so than does the finite element cell size.

3. The modified ESDU method and the FE-SI method produced similar estimates for bearing reaction forces, contact pressures, contact widths, and radial stiffness.

4. A steel and Nitinol 60 bearing carrying equivalent force per unit mass have very different contact pressure, contact widths, and deformations. For the example bearing and load intensity selected, the contact pressure of the Nitinol bearing was $1.01 \mathrm{GPa}$ compared to $1.48 \mathrm{GPa}$ for the steel bearing. The reduced stress is the combined influence of lesser density and smaller elastic modulus of Nitinol 60 . The elastic effect is the dominating influence.

5. A pitted bearing example was studied using the FE-SI method. For the situation of pit depth approximately twice the depth locating the maximum shear stress and static loading, a roller located directly over a pit became completely unloaded. In this example, the elastic movement of the outer ring increased to $0.0145 \mathrm{~mm}$ as compared to $0.010 \mathrm{~mm}$ for the undamaged bearing.

\section{ACKNOWLEDGMENTS}

This work was supported by the National Aeronautics and Space Administration, Fundamental Aeronautics Program, Subsonics Rotary Wing Project.
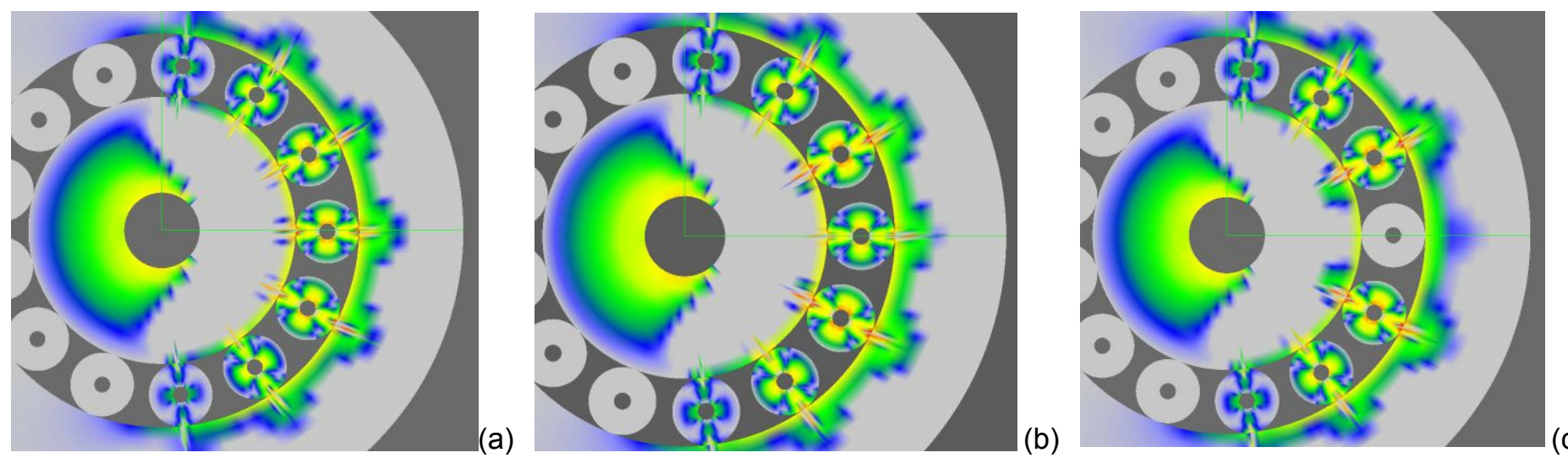

(c)

Figure 14. PATTERNS OF MAXIMUM PRINCIPLE STRESS FOR A BEARING WITHOUT AND WITH A PIT ON THE OUTER RACEWAY AT LOCATION OF X-AXIS. (a) BEARING WITHOUT PIT. (b) BEARING WITH PIT DEPTH 0.5 TIMES THE DEPTH TO MAXIMUM SHEAR (c) BEARING WITH PIT DEPTH 2.0 TIMES THE DEPTH TO MAXIMUM SHEAR. 


\section{REFERENCES}

[1] Vijayakar, S. M., Busby, H., Houser, D., 1988. "Linearization of multibody frictional contact problems". Computers and Structures, 29, pp. 569576.

[2] Vijayakar, S. M., Busby, H. R., Wilcox, L., 1989. "Finite element analysis of three-dimensional conformal contact with friction". Computers and Structures, 33, pp. 49-61.

[3] Vijayakar, S. M., 1991. "A combined surface integral and finite element solution for a three-dimensional contact problem". International Journal for Numerical Methods in Engineering, 31, pp. 524-54.

[4] Parker, R. G., Agashe, V., Vijayakar, S. M., 2000. "Dynamic response of a planetary gear system using a finite element/contact mechanics model". Journal of Mechanical Design, 122, pp. 304-310.

[5] Kahraman, A., Vijayakar, S. M., 2001. "Effect of internal gear flexibility on the quasi-static behavior of a planetary gear set". Journal of Mechanical Design, 123, pp. 408-415.

[6] Yuksel, C., Kahraman, A., 2004. "Dynamic tooth loads of planetary gear sets having tooth profile wear". Mechanism and Machine Theory, 39, pp. 695715 .

[7] Bajpai, P., Kahraman, A., Anderson, N.E., 2004. “A surface wear prediction methodology for helical gear pairs". Trans. of ASME, Journal of Tribology, 126.

[8] Guo, Y., Parker, R. G., 2010. "Dynamic modeling and analysis of a spur planetary gear involving tooth wedging and bearing clearance nonlinearity". European J. of Mechanics A/Solids, 29, pp. 1022103.

[9] Vijayakar, S. M., Sept. 29, 2009, "2D Modeling of gears and bearings with damaged surfaces", private communication.

[10] Guo, Y., Parker, R. G., 2011. "Stiffness calculation of rolling element bearings using a finite element/contact mechanics model," preprint for Mechanism and Machine Theory.

[11] Hertz, H., 1896. "On the contact of rigid elastic solids and on hardness", Miscellaneous Papers, MacMillan, London, pp.163-183.

[12] Jones, A. B., 1946. Analysis of Stresses and Deflections - New Departure Engineering Data, General Motors Corporation, Bristol, Conn.

[13] Harris, T. A., 1984. Rolling Bearing Analysis, 2nd edition. John Wiley and Sons, Inc.

[14] Hamrock, B. J., 1984. "Lubrication of machine elements", NASA RP 1126, National Aeronautics and Space Administration, Washington D.C.
[15] Engineering Sciences Data Unit, 1978. Contact stresses, Item 78035. Institution of Mechanical Engineers, London.

[16] Engineering Sciences Data Unit, 1995. Contact stresses, Item $78035 \mathrm{D}$. Institution of Mechanical Engineers, London.

[17] Antoine, J-F., et al., 2006. "Approximate analytical model for Hertzian elliptical contact problems". Trans. of ASME, Journal of Tribology, 128 (3).

[18] Jones, A. B., 1960. "A general theory for elastically constrained ball and radial roller bearings under arbitrary loads and speed conditions". J. of Basic Engineering, 82.

[19] R. Singh, T. Lim, 1990. "Vibration transmission through rolling element bearings in geared systems", NASA CR 4334, National Aeronautics and Space Administration, Washington, D.C.

[20] Lim, T.C, Singh, R., 1990. "Vibration transmission through rolling element bearings, part I: bearing stiffness formulation". J. of Sound and Vibration, 139.

[21] Lim, T.C., Singh, R., 1994. "Vibration transmission through rolling element bearings, part V: effect of distributed contact load on roller bearing stiffness matrix". J. of Sound and Vibration, 169.

[22] Johnson, K. L. 1987. Contact Mechanics, Cambridge University Press.

[23] Lim, T.C., Nov. 2010. Private e-mail communication.

[24] Vijayakar, S. M., 2004. Calyx User's Manual. http://ansol.us/Products/, accessed Dec. 29, 2010.

[25] ASME, 2006. Guide for Verification and Validation in Computational Solid Mechanics, ASME V\&V 102006. The American Society of Mechanical Engineers, New York.

[26] Roache, P. J., 1998. "Verification of codes and calculations", AIAA Journal, 36.

[27] Pepper, S., DellaCorte C., Glennon, G., 2010. "Lubrication of Nitinol 60". NASA TM-2010-216331, National Aeronautics and Space Administration, Washington D.C..

[28] DellaCorte, C., 2010. "Nickel-Titanium Alloys: Corrosion 'Proof' Alloys for Space Bearings, Components and Mechanism Applications". NASA TM-2010-216334, National Aeronautics and Space Administration, Washington D.C..

[29] Brown, G., et al, 2005. "NASA Glenn Research Center program in high power density motors for Aeropropulsion". NASA TM-2005-213800, National Aeronautics and Space Administration, Washington D.C.. 